The University of Maine

DigitalCommons@UMaine

Marine Sciences Faculty Scholarship

School of Marine Sciences

$3-20-2003$

\title{
Toward closure of upwelling radiance in coastal waters
}

\author{
Grace C. Chang \\ University of California, Santa Barbara \\ Tommy D. Dickey \\ University of California, Santa Barbara \\ Curtis D. Mobley \\ Sequoia Scientific, Inc. \\ Emmanuel Boss \\ University of Maine, emmanuel.boss@maine.edu \\ W. Scott Pegau \\ Oregon State University
}

Follow this and additional works at: https://digitalcommons.library.umaine.edu/sms_facpub

Part of the Marine Biology Commons

\section{Repository Citation}

Chang, Grace C.; Dickey, Tommy D.; Mobley, Curtis D.; Boss, Emmanuel; and Pegau, W. Scott, "Toward closure of upwelling radiance in coastal waters" (2003). Marine Sciences Faculty Scholarship. 152. https://digitalcommons.library.umaine.edu/sms_facpub/152

This Article is brought to you for free and open access by DigitalCommons@UMaine. It has been accepted for inclusion in Marine Sciences Faculty Scholarship by an authorized administrator of DigitalCommons@UMaine. For more information, please contact um.library.technical.services@maine.edu. 


\title{
Toward closure of upwelling radiance in coastal waters
}

\author{
Grace C. Chang, Tommy D. Dickey, Curtis D. Mobley, Emmanuel Boss, and W. Scott Pegau
}

\begin{abstract}
We present three methods for deriving water-leaving radiance $L_{w}(\lambda)$ and remote-sensing reflectance using a hyperspectral tethered spectral radiometer buoy (HyperTSRB), profiled spectroradiometers, and Hydrolight simulations. Average agreement for 53 comparisons between HyperTSRB and spectroradiometric determinations of $L_{w}(\lambda)$ was $26 \%, 13 \%$, and $17 \%$ at blue, green, and red wavelengths, respectively. Comparisons of HyperTSRB (and spectroradiometric) $L_{w}(\lambda)$ with Hydrolight simulations yielded percent differences of $17 \%(18 \%), 17 \%(18 \%)$, and $13 \%(20 \%)$ for blue, green, and red wavelengths, respectively. The differences can be accounted for by uncertainties in model assumptions and model input data (chlorophyll fluorescence quantum efficiency and the spectral chlorophyll-specific absorption coefficient for the red wavelengths, and scattering corrections for input ac-9 absorption data and volume scattering function measurements for blue wavelengths) as well as radiance measurement inaccuracies [largely differences in the depth of the $L_{u}(\lambda, z)$ sensor on the HyperTSRB]. () 2003 Optical Society of America
\end{abstract}

OCIS codes: $\quad 010.4450,120.0280,120.4640$.

\section{Introduction}

The total upwelling radiance just above the sea surface, $L_{u}(\lambda)$, is the sum of the water-leaving radiance $L_{w}(\lambda)$, which carries information about the water column, and the surface-reflected sky radiance $L_{r}(\lambda)$, which does not. The water-leaving radiance is thus the fundamental quantity underlying ocean color remote sensing. However, radiances can undergo large magnitude fluctuations that are due, for example, to passing clouds. It is therefore more common to use the remote-sensing reflectance

$$
R_{\mathrm{rs}}(\lambda)=\frac{L_{w}(\lambda)}{E_{d}(\lambda)}
$$

as the quantitative measure of ocean color information. Here, $E_{d}(\lambda)$ is the total (Sun plus background sky) plane irradiance incident onto the sea surface.

G. C. Chang (grace.chang@opl.ucsb.edu) and T. D. Dickey are with the Ocean Physics Laboratory, University of California at Santa Barbara, 6487 Calle Real, Suite A, Santa Barbara, California 93117 . C. D. Mobley is with Sequoia Scientific, Incorporated, Westpark Technical Center, 15317 NE 90th Street, Redmond, Washington 98052. E. Boss is with the School of Marine Sciences, University of Maine, 5741 Libby Hall, Orono, Maine 04469. W. S. Pegau is with the College of Oceanic and Atmospheric Sciences, Oregon State University, Corvallis, Oregon 97331.

Received 10 July 2002; revised manuscript received 10 October 2002.

0003-6935/03/091574-09\$15.00/0

(C) 2003 Optical Society of America
$R_{\mathrm{rs}}(\lambda)$ is an apparent optical property (AOP) that retains the spectral information of the water-leaving radiance, but which is largely free of its magnitude variability.

Algorithms and models have been developed to relate remote-sensing reflectance measurements to in-water constituents including chlorophyll concentration; spectral backscattering coefficients; spectral absorption coefficients; and spectral absorption coefficients separated into phytoplankton, detrital, and gelbstoff constituents (e.g., Garver et al., ${ }^{1}$ Tassan, ${ }^{2}$ Roesler and Perry, ${ }^{3}$ Gould and Arnone, ${ }^{4}$ O'Reilly et $a l .{ }^{5} \mathrm{He}$ et $\left.a l .{ }^{6}\right)$. Recent efforts have focused on use of remote-sensing data to resolve water column vertical structures and to detect subsurface features such as internal waves, sediment plumes, bottom type, and bathymetry. ${ }^{4,7-10}$

All these techniques for retrieving environmental information from remotely made radiance measurements rely on accurate determination of the waterleaving radiance or remote-sensing reflectance and on establishing robust relationships between the water-leaving radiance and the in-water constituents or other quantities of interest. Because only the total upwelling radiance can be directly measured, it is necessary to estimate the water-leaving radiance. Several techniques can be used to obtain $L_{w}(\lambda)$, and each has its advantages and limitations. If $L_{u}(\lambda)$ is measured above the surface, an estimate of $L_{w}(\lambda)$ can be made through subtraction of an estimate of the surface-reflected radiance $L_{r}(\lambda)$, which itself cannot be directly measured. If the underwater upwelling 
radiance is measured at multiple depths $z$ below the sea surface, this $L_{u}(\lambda, z)$ can be extrapolated upward through the water column and sea surface to estimate $L_{w}(\lambda)$. It is then unnecessary to estimate the surface-reflected radiance, but other uncertainties arise because of the extrapolation. If the inherent optical properties (IOPs) [namely, the spectral absorption coefficient and the spectral volume scattering function (VSF)] of the water body are known (along with information about the incident sky and solar radiance, the sea state, and the sea bottom), then radiative transfer numerical models can be used to compute the water-leaving radiance. This method to estimate $L_{w}(\lambda)$ is constrained by the accuracy of the various inputs to the numerical model and by any approximations made in the solution of the radiative transfer equation.

To understand the errors that may occur in the retrieved environmental quantities of ultimate interest, it is clearly necessary first to understand the errors associated with different techniques for the determination of $L_{w}(\lambda)$ and $R_{\mathrm{rs}}(\lambda)$. It is not yet possible to say if any particular method for estimating $L_{w}(\lambda)$ is superior to the other methods, or even how various methods compare in different situations. Estimation of $L_{w}(\lambda)$ from above-surface measurements has been discussed recently by Mobley ${ }^{11}$ and Toole et al. ${ }^{12}$ In this paper we compare methods for obtaining $L_{w}(\lambda)$ from underwater measurements and from radiative transfer calculations. In particular, we show methods for deriving $L_{w}(\lambda)$ and $R_{\mathrm{rs}}(\lambda)$ using a tethered radiometric buoy, profiled spectroradiometers, and radiative transfer calculations using measured boundary conditions and IOPs as inputs. We examine the extent to which current technology gives closure between the two in situ measurement methods as well as with radiative transfer modeling in turbid coastal waters.

During the past few years, novel in situ instrumentation has been developed for measurements of upwelling radiance and downwelling irradiance with hyperspectral capabilities $[<5-\mathrm{nm}$ wavelength resolution for $380 \leq \lambda \leq 800 \mathrm{~nm}$; e.g., Satlantic, Inc. HyperTSRB (hyperspectral tethered spectral radiometer buoy) and MiniSpecs, and HOBI Labs (Hydro-Optics, Biology, and Instrumentation Laboratories) HydroRad]. In situ measurements provide a link between remotely sensed data and optical properties in the water column and near the seafloor, which is important for ground-truthing and algorithm development. ${ }^{13}$ However, several problems exist for the interpretation of in situ radiometric measurements and their comparison to remote-sensing data. In situ radiometric instruments are necessarily deployed below the sea surface for measurements of $L_{u}(\lambda, z)$ from which $L_{w}(\lambda)$ must be derived. Radiometers are usually profiled, moored, or tethered from just below the sea surface down to the $1 \%$ light level, but interpretation of near-surface data is complicated by time-varying surface roughness effects. These effects include scattering by whitecaps and bubbles $^{14,15}$ and light focusing by surface waves. ${ }^{16}$

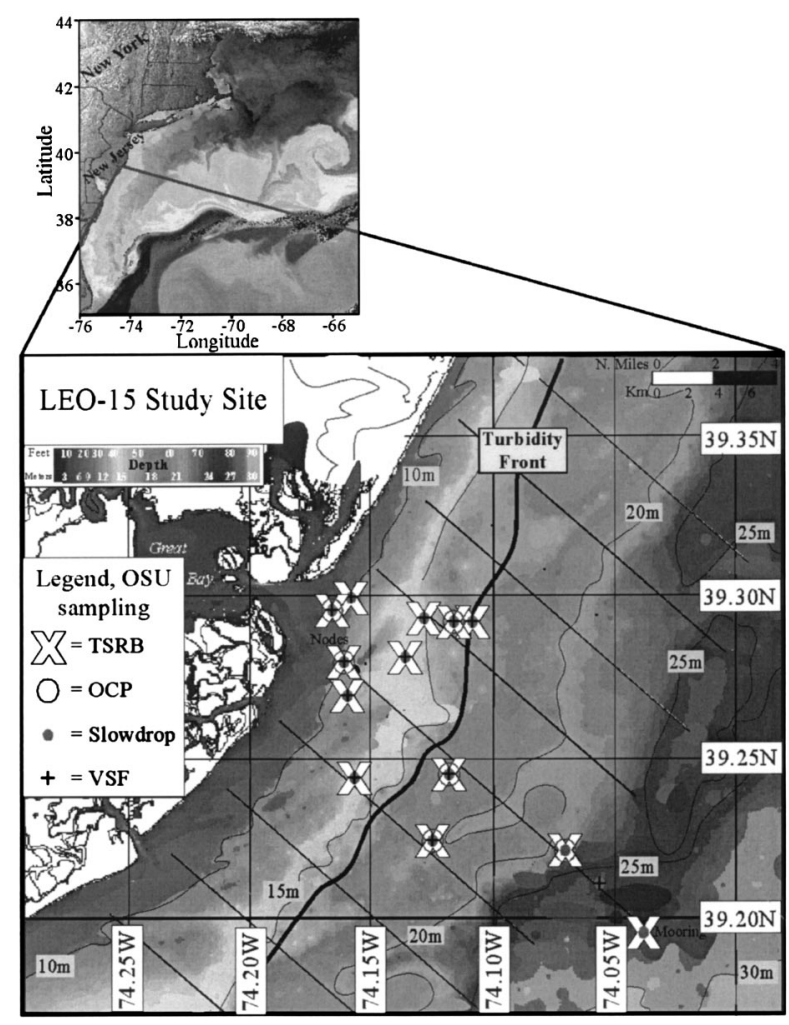

Fig. 1. LEO-15 site map showing the locations of the 53 measurements made during the HyCODE experiment between 21 and 27 July 2000. Depth contours and location of the turbidity front are approximate. OSU, Oregon State University.

In-water instruments are also subject to self-shading effects. ${ }^{17,18}$ Toole et al. ${ }^{12}$ investigated a variety of other environmental effects (Sun angle, cloud cover, wind speed, and viewing geometry) on radiometric determinations. They found wind speed to be the major factor affecting measurement uncertainty.

\section{Methods}

The present study is part of the Hyperspectral Coastal Ocean Dynamics Experiment (HyCODE) sponsored by the U.S. Office of Naval Research. One of the central goals of the HyCODE program is to utilize hyperspectral imagery to improve understanding of the diverse processes controlling IOPs in the coastal ocean. The program also aims to develop operational ocean color algorithms for the optically shallow ocean where bottom reflectance is important and the optically deep ocean where bottom reflectance is unimportant.

The optical measurements presented here were made during the 2000 HyCODE field experiment at the Long-term Ecological Observatory site (LEO-15) off the coast of New Jersey in water depths of less than $25 \mathrm{~m}$ (Fig. 1). Three methods were employed to measure or compute spectral radiance and irradiance: (1) HyperTSRB, (2) Ocean Color Profiler (OCP-100) free-fall spectroradiometers, and (3) Hydrolight 4.1 radiative transfer modeling with IOPs measured in situ as input. In this paper we focus on 
53 measurements made between 21 and 27 July 2000 from the R/V Northstar (Fig. 1).

\section{A. Hyperspectral Tethered Spectral Radiometer Buoy}

The Satlantic, Inc. HyperTSRB measures upwelling radiance at $0.66 \mathrm{~m}$ below the sea surface, $L_{u}(\lambda, 0.66$ $\mathrm{m})$, and downwelling irradiance just above the sea surface, $E_{d}\left(\lambda, 0^{+} \mathrm{m}\right)$, with 256 channels between wavelengths of 400 and $800 \mathrm{~nm}(\sim 3.3-\mathrm{nm}$ spectral resolution). ${ }^{19}$ The methods used to extrapolate HyperTSRB data to the surface are described in Subsection 2.B. The buoy instruments were tethered at least $30 \mathrm{~m}$ away from the ship to avoid vessel shadow effects. Data were averaged over the HyperTSRB sampling period (between $\sim 2$ and $48 \mathrm{~min}$ ). Selfshading effects were removed from data by use of methods presented in Leathers et al. ${ }^{18}$

\section{B. Ocean Color Profilers}

A Satlantic, Inc. OCP-100 with seven-wavelength radiance and irradiance detectors $(412,442,490,532$, 555,590 , and $682 \mathrm{~nm}$ ) was used in a profiling mode to make radiometric measurements. The radiometers were mounted on top of a small cage called Suitcase that was ballasted to provide a slow descent rate $(0.2$ $\mathrm{m} \mathrm{s}^{-1}$ on average). The radiometers were mounted on horizontal extensions from the cage to minimize the effects of the cage on the measurements. The two sensors were mounted within $10 \mathrm{~cm}$ and $1 \mathrm{~m}$ of each other in the vertical and horizontal, respectively. The platform was profiled approximately $15 \mathrm{~m}$ from the boat to minimize ship-shadowing effects. During the processing, radiometer data were merged with the above-water measurements, and the 10 -cm difference in depth of the sensors was taken into account. A tilt sensor was also mounted on the Suitcase package for quality control measures; data were discarded when the sensor tilted $>5^{\circ}$.

We utilized OCP data to compute the diffuse attenuation coefficient for upwelling radiance $K_{L}(\lambda)$ :

$$
\begin{aligned}
K_{L}(\lambda) & =-\frac{\mathrm{d}}{\mathrm{d} z}\left[\ln L_{u}(\lambda, z)\right], \\
& =-\frac{1}{\Delta z} \ln \frac{L_{u}\left(\lambda, z_{2}\right)}{L_{u}\left(\lambda, z_{1}\right)},
\end{aligned}
$$

where $z_{2}$ and $z_{1}$ are different depths measured by the OCP, and $z_{2}>z_{1}$. Depths $z_{1}$ and $z_{2}$ were chosen within the upper water column where computed $K_{L}(\lambda)$ was relatively constant. $L_{u}(\lambda, z)$ measured by the HyperTSRB and OCPs was then extrapolated to depths of $0.66 \mathrm{~m}$ below the sea surface, just below the sea surface $\left(z=0^{-}\right)$, and just above the sea surface $\left(z=0^{+}\right)$by use of $K_{L}(\lambda)$ and the $n$-squared law for radiance ${ }^{20}$ :

$$
L_{w}(\lambda)=\frac{t}{n^{2}} L_{u}\left(\lambda, 0^{-}\right),
$$

where $n$ is the real index of refraction of water $(n \approx$ 1.34) and $t$ is the radiance transmittance of the sur- face $(t \approx 0.98) .{ }^{20}$ We then computed the remotesensing reflectance using $L_{w}(\lambda)$ derived from HyperTSRB and OCP measurements and $E_{d}(\lambda)$ measured by the HyperTSRB.

\section{Inherent Optical Properties}

IOPs were measured concurrently with HyperTSRB and OCP data. We obtained profiles of optical properties by using the free-falling slow descent rate optics platform (Slowdrop). Instruments on Slowdrop included two spectral absorption-attenuation meters (ac-9s), ${ }^{21}$ a conductivity-temperature-depth sensor, and a fluorometer. To determine the contribution of colored dissolved materials to the total absorption coefficient, a $0.2-\mu \mathrm{m}$ filter (Gelman Suporcap 100) was attached to the inlet of one of the ac-9s. Both instruments were calibrated daily with optically pure water as a reference (Barnstead NANOpure). Chlorophyll- $a$ concentration was inferred with the fluorometer and was computed with the spectral absorption data and the method presented in Chang. ${ }^{22}$ VSFs at $532 \mathrm{~nm}$ were measured at various discrete depths within the mixed layer (generally $<5$-m water depth). VSFs over a range of scattering angles $\left(0.5^{\circ}\right.$ to $177.6^{\circ}, 0.6^{\circ}$ resolution) were quantified by use of a prototype VSF meter. ${ }^{23}$ Total (diffuse sky and direct solar) irradiances for Hydrolight 4.1 input were obtained by the above-surface downwelling irradiance sensor on the HyperTSRB.

Wind speeds were recorded at a nearby meteorological tower, and cloud cover was estimated at the time of sampling. The Sun angle was computed from latitude and longitude from the shipboard global positioning system and sampling dates and times. The measured IOPs and ancillary information about wind speed and sky conditions provided Hydrolight with the necessary information for solving the unpolarized radiative transfer equation. Pure-water absorption coefficients were taken from Pope and Fry. ${ }^{24}$ The Prieur and Sathyendranath ${ }^{25}$ phytoplankton-specific absorption spectrum was used to determine how much light was absorbed by chlorophyll so that measured chlorophyll fluorescence could be included in the Hydrolight simulations. In all cases, waters were optically deep. Initial Hydrolight runs with and without Raman scatter showed less than $1 \%$ difference in $L_{w}(\lambda)$; thus Raman scatter was not included in subsequent runs. It was concluded that Raman scattering is negligible at the LEO-15 site because of the relatively high concentrations of chlorophyll. ${ }^{26,27}$

\section{Instrument Accuracies}

We compared HyperTSRB downwelling irradiance data with similar measurements made aboard the R/V Northstar using a Satlantic, Inc. Multichannel Visible Detector System (MVDS) sensor. The MVDS measures at seven wavelengths in the visible and was located $>30 \mathrm{~m}$ from the HyperTSRB. Measurement results were generally within $10 \%$ of each other except during periods of high haze and patchy clouds. $^{28}$ All radiometers were field calibrated at 
least every three days against a stable light source. The drifts of the HyperTSRB, OCP, and MVDS were found to be $<3 \%$ for both the irradiance and the radiance sensors. Further accuracy information for radiometers can be found in Hooker et al. ${ }^{29}$

Accurate radiometric measurements are extremely difficult to make because of extensive sources of errors associated with environmental effects and instrument design. These include instrument tilt for the HyperTSRB (no tilt sensor was mounted on the buoy), shadowing, wave focusing, depth differences, and wavelength shifts related to the misalignment of optical filters. The quantification of the uncertainties in the accuracy of the radiometers is presented in Section 4.

The precision of the ac-9 after temperature and scattering corrections is reported to be $0.002 \mathrm{~m}^{-1}$. The accuracy is dependent on wavelength; uncertainty in scattering corrections for particulate absorption can result in inaccuracies of up to $20 \%$ in the blue wavelengths (412 and $442 \mathrm{~nm}$ ). ${ }^{30}$ Reported ac-9 calibration accuracy is $0.005 \mathrm{~m}^{-1}$ in the red and green wavelengths. VSF meter accuracy was laboratory tested with monodisperse spheres. Results compared well (differences within $\sim 10 \%$ ) with theoretical Mie calculations (Fig. 5 in Lee and Lewis ${ }^{23}$ ).

\section{Results}

\section{A. Oceanographic Setting}

The LEO-15 study site is an area of considerable seasonal and interannual variability, semidiurnal tides, internal solitary waves, upwelling, fronts, coastal jets, eddies, storms, and river and estuarine outflows. Several of these processes were observed during the summer 2000 field study. In-water optical properties were heavily influenced by a water mass-turbidity front that was located $\sim 8-15 \mathrm{~km}$ from shore. This front separated relatively turbid nearshore waters ( $15 \mathrm{~km}$ from shore) from clearer offshore waters (15-25 km from shore). ${ }^{31}$ Particulate absorption, compared with dissolved matter absorption, dominated total absorption nearshore at $440 \mathrm{~nm}$. In contrast, particulate and dissolved matter each accounted for roughly $50 \%$ of total absorption at $\lambda=440 \mathrm{~nm}>15 \mathrm{~km}$ from shore. Small-scale (of the order of a few kilometers) convergence and divergence zones formed from the interaction of semidiurnal tides with mean currents and the water mass-turbidity front. These convergence and divergence zones, coupled with the presence of the horizontal gradient of particulate matter from nearshore (higher) to offshore (lower), formed small-scale ( $\sim 2$ $5-\mathrm{km})$ patches of particles. Further details about the relationships between physical processes and optical properties at the LEO-15 site in the summer of 2000 can be found in Chang et al. ${ }^{31}$

\section{B. Upwelling Radiance and Remote-Sensing Reflectance} Spectra

We utilized Eqs. (2) and (3) to extrapolate OCPmeasured upwelling radiance spectra to $0.66 \mathrm{~m}$ below
Table 1. Average Absolute Value of Percent Differences Computed with Eq. (4) and $r^{2}$ Values between HyperTSRB and OCP $L_{u}(\lambda, 0.66 \mathrm{~m})$

\begin{tabular}{lcccccccc}
\hline & \multicolumn{7}{c}{ Wavelength } \\
\cline { 2 - 7 } \multicolumn{1}{c}{ Location } & 412 & 442 & 490 & 532 & 555 & 590 & 682 & $r^{2}$ Value \\
\hline Inshore $^{a}$ & 39 & 37 & 31 & 20 & 19 & 11 & 25 & 0.97 \\
Offshore $^{a}$ & 26 & 23 & 17 & 11 & 10 & 18 & 11 & 0.96 \\
Total average & 35 & 32 & 26 & 17 & 16 & 13 & 20 & 0.97 \\
\hline
\end{tabular}

${ }^{a}$ In relation to the turbidity front. See Chang et al. ${ }^{31}$ for details regarding optical properties inshore and offshore of the turbidity front.

the sea surface, just below the sea surface $\left(0^{-}\right)$, and just above the sea surface $\left(0^{+}\right)$. HyperTSRB $L_{u}(\lambda$, $0.66 \mathrm{~m}$ ) was extrapolated to $z=0^{-}$and $0^{+}$. These resulting upwelling and water-leaving radiance spectra were then compared with each other as well as with Hydrolight-computed upwelling $(z=0.66 \mathrm{~m})$ and water-leaving radiance. HyperTSRB and OCP comparisons of $L_{u}(\lambda, 0.66 \mathrm{~m})$ and $L_{w}(\lambda)$ at the SeaViewing Wide Field-of-View Sensor (SeaWiFS) wavelengths are shown in Tables 1 and 2. Figure 2 illustrates the comparisons among the HyperTSRB, OCP, and Hydrolight-computed $L_{u}(\lambda, 0.66 \mathrm{~m})$. Errors are reported as percent differences and calculated with the following equation:

$$
\operatorname{diff}(\lambda)=100 \times\left\{\frac{\left[L_{u}(\lambda, z)_{1}-L_{u}(\lambda, z)_{2}\right]}{0.5\left[L_{u}(\lambda, z)_{1}+L_{u}(\lambda, z)_{2}\right]}\right\},
$$

where $L_{u}(\lambda, z)_{1}$ is upwelling or water-leaving radiance measured by the HyperTSRB or OCP and $L_{u}(\lambda$, $z)_{2}$ is upwelling or water-leaving radiance measured or estimated with OCP or Hydrolight. Tables 1-4 show averaged percent differences of several (up to 30) measurement stations; therefore absolute values of percent differences are presented. Comparisons between instrument-measured and Hydrolightcomputed upwelling and water-leaving radiances are shown in Tables 3 and 4 and Figs. 2 and 3. Remotesensing reflectance spectra are shown in Fig. 4 . We do not show $R_{\mathrm{rs}}(\lambda)$ statistical information because it is the same as that for water-leaving radiance; we used the same HyperTSRB-measured $E_{d}(\lambda)$ for all remotesensing reflectance calculations.

The spectral shapes of upwelling radiance and remote-sensing reflectance were dependent on sampling location. Inshore of the water mass-turbidity

Table 2. Average Absolute Value of Percent Differences Computed with Eq. (4) and $r^{2}$ Values between HyperTSRB and OCP $L_{w}(\lambda)$

\begin{tabular}{lrrrrrrrr}
\hline & \multicolumn{7}{c}{ Wavelength } \\
\cline { 2 - 7 } \multicolumn{1}{c}{ Location } & 412 & 442 & 490 & 532 & 555 & 590 & 682 & $r^{2}$ Value \\
\hline Inshore $^{a}$ & 33 & 31 & 24 & 14 & 13 & 12 & 21 & 0.95 \\
Offshore $^{a}$ & 21 & 18 & 12 & 8 & 8 & 26 & 10 & 0.93 \\
Total average $^{*} 30$ & 27 & 21 & 12 & 12 & 16 & 17 & 0.95 \\
\hline
\end{tabular}

${ }^{a}$ In relation to the turbidity front. See Chang et al. ${ }^{31}$ for details regarding optical properties inshore and offshore of the turbidity front. 

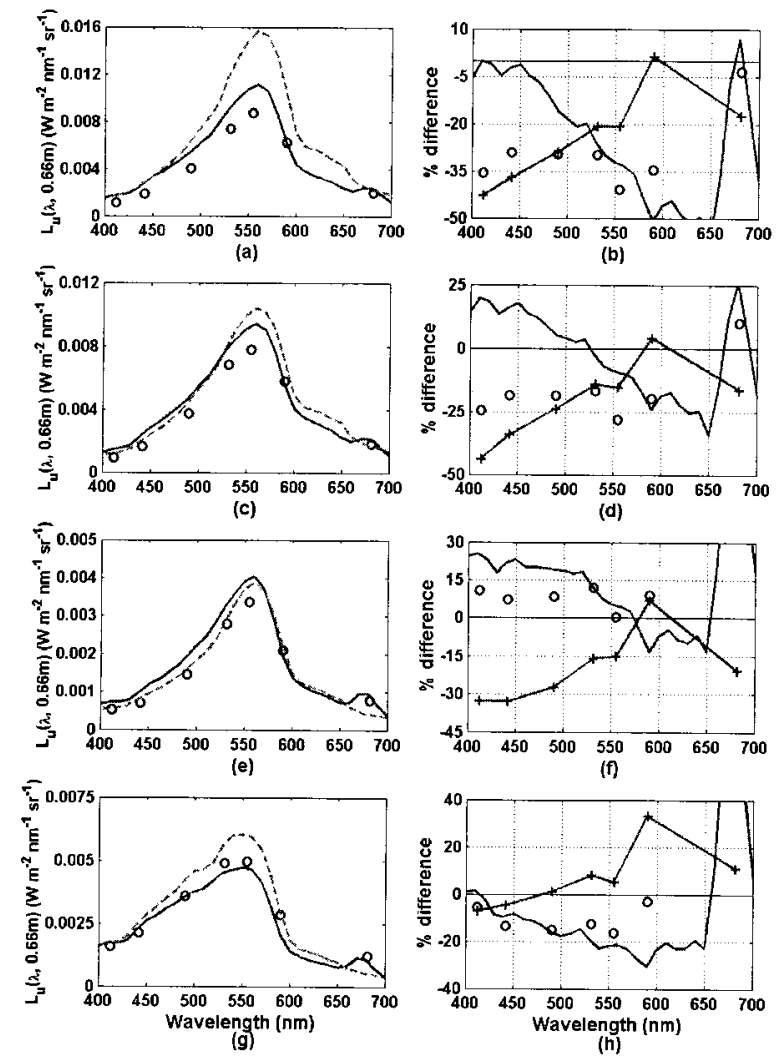

Fig. 2. HyperTSRB (solid curves), OCP (open circles), and Hydrolight-computed (dashed curves) comparisons of $L_{u}(\lambda, 0.66 \mathrm{~m})$ at the SeaWiFS wavelengths: (a) and (b) $\sim 5 \mathrm{~km}$ offshore of the turbidity front $\left(39.37^{\circ} \mathrm{N}, 74.21^{\circ} \mathrm{W}\right)$; (c) and (d) $\sim 5 \mathrm{~km}$ inshore of the front $\left(39.46^{\circ} \mathrm{N}, 74.26^{\circ} \mathrm{W}\right)$, (e) and (f) at the turbidity front $\left(39.41^{\circ} \mathrm{N}, 74.20^{\circ} \mathrm{W}\right)$; $(\mathrm{g})$ and $(\mathrm{h}) \sim 12 \mathrm{~km}$ offshore of the turbidity front $\left(39.37^{\circ} \mathrm{N}, 74.13^{\circ} \mathrm{W}\right)$. Differences among the three methods, calculated by Eq. (4), are shown in the right-hand column.

front, $L_{w}(\lambda)$ and $R_{\mathrm{rs}}(\lambda)$ spectra were relatively constant in shape except $<2 \mathrm{~km}$ from the mouth of Great Bay. In this nearshore region, large peaks were observed at the 560 -nm wavelength for normalized $R_{\mathrm{rs}}(\lambda) / R_{\mathrm{rs}}(680 \mathrm{~nm}) . \quad R_{\mathrm{rs}}(\lambda) / R_{\mathrm{rs}}(680-\mathrm{nm})$ spectra offshore of the water mass-turbidity front were significantly different in shape compared with the inshore

Table 3. Average Absolute Value of Percent Differences Computed with Eq. (4) and $r^{2}$ Values between HyperTSRB and Hydrolight and OCP and Hydrolight (in parentheses) for $L_{u}(\lambda, 0.66 \mathrm{~m})$

\begin{tabular}{lrrrrrrrr}
\hline & \multicolumn{7}{c}{ Wavelength } & \\
\cline { 2 - 7 } \multicolumn{1}{c}{ Location } & 412 & 442 & 490 & 532 & 555 & 590 & 682 & $r^{2}$ Value \\
\hline Inshore $^{a}$ & 17 & 16 & 13 & 15 & 17 & 25 & 43 & 0.96 \\
& $(21)$ & $(19)$ & $(18)$ & $(17)$ & $(23)$ & $(16)$ & $(31)$ & $(0.99)$ \\
Offshore $^{a}$ & 14 & 11 & 12 & 17 & 19 & 32 & 69 & 0.95 \\
& $(17)$ & $(14)$ & $(15)$ & $(18)$ & $(20)$ & $(22)$ & $(69)$ & $(0.98)$ \\
Total average & 14 & 12 & 12 & 16 & 19 & 29 & 45 & 0.96 \\
& $(21)$ & $(18)$ & $(18)$ & $(18)$ & $(23)$ & $(19)$ & $(38)$ & $(0.99)$ \\
\hline
\end{tabular}

${ }^{a}$ In relation to the turbidity front. See Chang et al..$^{31}$ for details regarding optical properties inshore and offshore of the turbidity front.

Table 4. Average Absolute Value of Percent Differences Calculated with Eq. (4) and $r^{2}$ Values between HyperTSRB and Hydrolight and OCP and Hydrolight (in parentheses) for $L_{w}(\lambda)$

\begin{tabular}{lrrrrrrrr}
\hline & \multicolumn{7}{c}{ Wavelength } & \\
\cline { 2 - 7 } \multicolumn{1}{c}{ Location } & 412 & 442 & 490 & 532 & 555 & 590 & 682 & $r^{2}$ Value \\
\hline Inshore $^{a}$ & 21 & 24 & 19 & 7 & 6 & 13 & 10 & 0.96 \\
& $(26)$ & $(20)$ & $(16)$ & $(15)$ & $(22)$ & $(17)$ & $(17)$ & $(0.99)$ \\
Offshore $^{a}$ & 8 & 9 & 15 & 19 & 23 & 36 & 21 & 0.92 \\
& $(17)$ & $(17)$ & $(14)$ & $(18)$ & $(22)$ & $(19)$ & $(21)$ & $(0.98)$ \\
Total average & 16 & 18 & 18 & 12 & 14 & 23 & 13 & 0.94 \\
& $(22)$ & $(17)$ & $(14)$ & $(16)$ & $(22)$ & $(18)$ & $(20)$ & $(0.98)$ \\
\hline
\end{tabular}

${ }^{a}$ In relation to the turbidity front. See Chang et al. ${ }^{31}$ for details regarding optical properties inshore and offshore of the turbidity front.

spectra, with a shoulder of higher values between 400 and $520 \mathrm{~nm}$ [Fig. 4(g)].

\section{Discussion}

The agreement between the HyperTSRB and the OCP measurements of $L_{u}(\lambda, 0.66 \mathrm{~m})$ is within $\sim 25 \%$

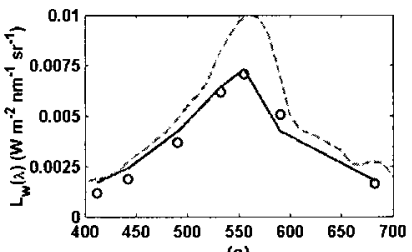

(a)

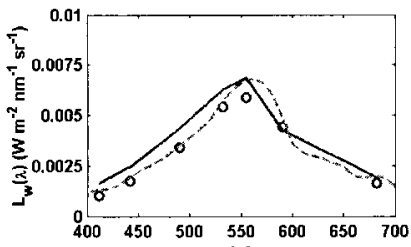

(c)

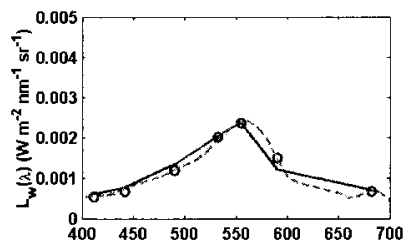

(e)

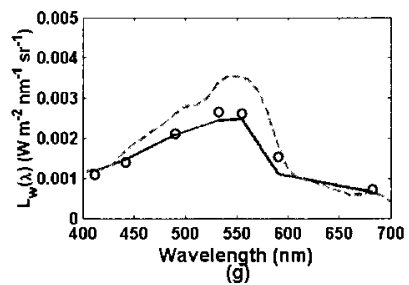

Fig. 3. Comparisons of HyperTSRB (solid curves), OCP (open circles), and Hydrolight-computed (dashed curves) $L_{w}(\lambda)$ : (a) and (b) $\sim 5 \mathrm{~km}$ offshore of the turbidity front $\left(39.37^{\circ} \mathrm{N}, 74.21^{\circ} \mathrm{W}\right) ;(\mathrm{c})$ and (d) $\sim 5 \mathrm{~km}$ inshore of the front $\left(39.46^{\circ} \mathrm{N}, 74.26^{\circ} \mathrm{W}\right)$; (e) and (f) at the turbidity front $\left(39.41^{\circ} \mathrm{N}, 74.20^{\circ} \mathrm{W}\right) ;(\mathrm{g})$ and $(\mathrm{h}) \sim 12 \mathrm{~km}$ offshore of the turbidity front $\left(39.37^{\circ} \mathrm{N}, 74.13^{\circ} \mathrm{W}\right)$. Differences among the three methods, calculated by Eq. (4), are shown in the right-hand column. 


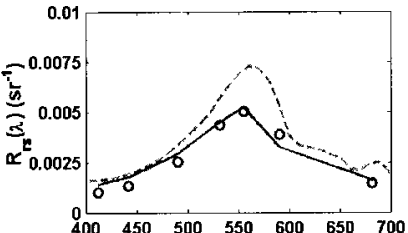

(a)

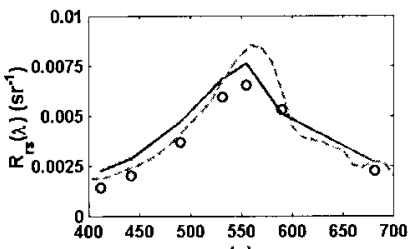

(c)
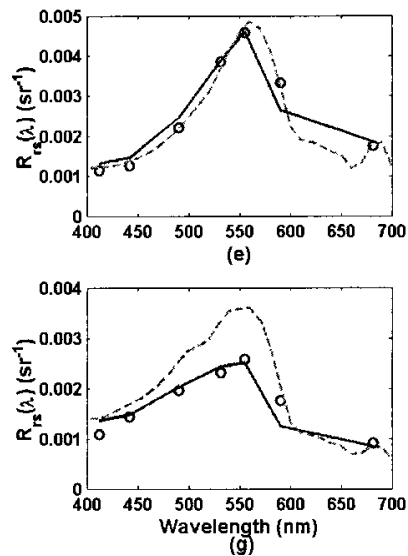

(g)

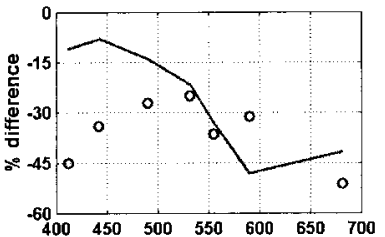

(b)

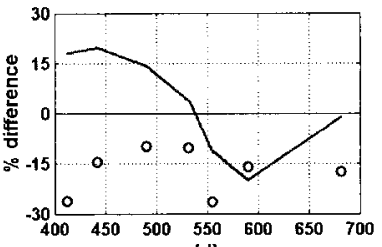

(d)
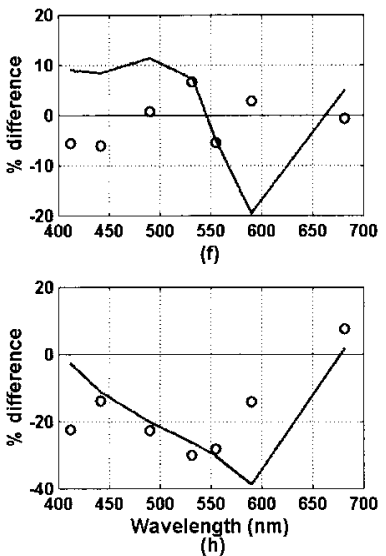

(h)
Fig. 4. $R_{\mathrm{rs}}(\lambda)$ derived from HyperTSRB (solid curves) and OCP (open circles) measurements and Hydrolight simulations (dashed curves): (a) and (b) $\sim 5 \mathrm{~km}$ offshore of the turbidity front $\left(39.37^{\circ} \mathrm{N}, 74.21^{\circ} \mathrm{W}\right)$; (c) and (d) $\sim 5 \mathrm{~km}$ inshore of the front $\left(39.46^{\circ} \mathrm{N}, 74.26^{\circ} \mathrm{W}\right)$; (e) and (f) at the turbidity front $\left(39.41^{\circ} \mathrm{N}\right.$, $74.20^{\circ} \mathrm{W}$ ); (g) and (h) $\sim 12 \mathrm{~km}$ offshore of the turbidity front $\left(39.37^{\circ} \mathrm{N}, 74.13^{\circ} \mathrm{W}\right)$. Differences among the methods, calculated by Eq. (4), are shown in the right-hand column.

at $412 \mathrm{~nm}$ to $13 \%$ at $590 \mathrm{~nm}$ and averaged $\sim 25 \%$ over all wavelengths (Table 1 and Fig. 2). This is remarkable given that radiances are difficult optical parameters to measure accurately because of the many variables affecting the measurement (see Subsection 4.A.1). More remarkable, however, is that we find percent differences of $<25 \%$ between Hydrolight-modeled and HyperTSRB- and OCPmeasured radiances (except in the red wavelengths; Tables 3 and 4). These results, however, are not as promising for ocean color satellite measurement goals. For example, the moderate-resolution imaging spectroradiometer (MODIS) goal is to estimate normalized $L_{w}(\lambda)$ to within $5 \%$ in the blue wavelengths. This would be extremely difficult given that in situ measurement capabilities are shown to be accurate to within $\sim 25 \%$.

\section{A. Sources of Error}

\section{Instrument Measurement Uncertainties}

HyperTSRB and OCP water-leaving radiance mismatches (Table 2) are most likely due to the extrap- olation of subsurface measurements to above-surface values. Environment and instrument design issues contributing to measurement differences between the HyperTSRB and the OCPs include instrument tilt, errors in wavelength registration, self-shading, and depth of the $L_{u}(\lambda, z)$ sensor on the HyperTSRB. We quantified possible instrument measurement errors from up to $5^{\circ}-10^{\circ}$ tilting of the HyperTSRB by removing the top and bottom one third of the data within the sampling period, i.e., outliers, before averaging. This new value was then compared with the average of the entire data set. Results show that possible tilt errors were negligible $(<1 \%)$. Temperature effects may cause shifts in wavelengths of up to $\pm 5 \mathrm{~nm}$ in radiometers. Average errors caused by such wavelength shifts were found to be within $\pm 6 \%$, with the largest errors found in the blue to green wavelengths.

Average self-shading errors have been reported to be approximately 5\% for measurements of upwelling radiance and are highly dependent on solar angle and water column absorption. ${ }^{17}$ Leathers et al. ${ }^{18}$ found TSRB self-shading errors for a solar angle of $0^{\circ}$ and scattering to an absorption ratio of 2.0 (4.0) of up to $33 \%(26 \%)$ and $58 \%(37 \%)$ for absorption values of 0.2 and $0.5 \mathrm{~m}^{-1}$, respectively. These are the ranges of scattering to absorption ratios and absorption values found during the 2000 HyCODE experiment. Selfshading errors were corrected for HyperTSRB data by use of the correction factors in Leathers et al., ${ }^{18}$ but not for OCP data because the needed correction factors for the geometry of that instrument are not available.

Changes in the distance between the sea surface and the depth of the $L_{u}(\lambda, z)$ sensor on the HyperTSRB may cause errors in measurements of $L_{u}(\lambda$, $0.66 \mathrm{~m})$. We determined the errors by comparing OCP-measured $L_{u}(\lambda, 0.66 \mathrm{~m}), L_{u}(\lambda, 0.71 \mathrm{~m})$, and $L_{u}(\lambda$, $0.76 \mathrm{~m}$ ). Results show that a 5-cm change in depth of the HyperTSRB $L_{u}(\lambda, z)$ sensor would result in changes in $L_{u}(\lambda, z)$ of up to $14.4 \%, 21.7 \%$, and $12.6 \%$ in the blue, green, and red wavelengths, respectively. A $10-\mathrm{cm}$ change would cause errors of $17.6 \%, 22.3 \%$, and $14.8 \%$ in the blue, green, and red wavelengths, respectively.

The spectral shape of the differences associated with changes in depth of the $L_{u}(\lambda, z)$ sensor on the HyperTSRB is similar in shape to the differences between HyperTSRB and OCP measurements that can be seen in Fig. 2. Therefore uncertainties of the measurements, particularly depth differences, can account for the $\sim 25 \%$ difference found between $\mathrm{Hy}$ perTSRB and OCP determinations of $L_{u}(\lambda, z)$ (Table 1 ; Fig. 2), with HyperTSRB $L_{u}(\lambda, z)$ sensor changes in depth accounting for the spectral shape of the errors.

\section{Hydrolight Simulation Uncertainties}

The values at the chlorophyll fluorescence peak $(\sim 680 \mathrm{~nm})$ are affected by both the assumed spectral chlorophyll-specific absorption coefficient $a_{\mathrm{ph}} *(\lambda)$ and the chlorophyll fluorescence quantum efficiency, which is taken to be constant (0.02) in these Hydro- 
light simulations. The natural variability of fluorescence quantum efficiency has been found to be between 0.01 and 0.03 (Westberry ${ }^{32}$ and references therein). Therefore the relatively larger errors found in the chlorophyll fluorescence band (Tables 3 and 4) can be attributed to Hydrolight simulation assumptions used in the computation of chlorophyll fluorescence and assumptions about $a_{\mathrm{ph}}{ }^{*}(\lambda)$. The natural variability of $a_{\mathrm{ph}} *(\lambda)$ is between 0.008 and $0.023 \mathrm{~m}^{-1}$ at $676 \mathrm{~nm} .{ }^{25}$ Ideally, measured values of $a_{\mathrm{ph}} *(\lambda)$ should be input into the model for more accurate AOP outputs. Unfortunately, no measurements of fluorescence quantum yield and no concurrent measurements of $a_{\mathrm{ph}} *(\lambda)$ were made during the 2000 HyCODE experiment.

Additional possible sources of error for the derivation of $L_{w}(\lambda)$ include assumptions about the VSF and scattering corrections. Mobley et al. ${ }^{33}$ found that calculations of radiometric quantities and AOPs from IOPs are sensitive to the backscatter fraction and the shape of the scattering phase function at intermediate and backward-scattering angles. We assume that the shape of the measured VSFs were independent of wavelength. Therefore relatively small errors in measurements of the VSF at $532 \mathrm{~nm}$ with the prototype instrument can lead to significant differences in Hydrolight calculations of $L_{w}(\lambda)$ at other wavelengths. Also, differences may be due to the presence of vertical structure of optical properties in the water column because VSF measurements were made at single depths and assumed to be constant throughout the modeled water column. See Mobley et $a l .{ }^{33}$ for a sensitivity analysis of VSF effects on AOPs and Chang et al. ${ }^{31}$ for a description of the water column vertical structure of optical properties at the LEO-15 site.

Errors in the blue wavelengths $(412-490 \mathrm{~nm}$; Tables 3 and 4) may be due to uncertainties in the scattering corrections for ac-9 measured absorption and scattering coefficients, which are used as inputs to Hydrolight. As mentioned in Subsection 2.D, uncertainties in scattering corrections can result in errors in absorption of up to $20 \%$ and in scattering of approximately 5-10\%.30 These errors are then propagated throughout the radiative transfer equations in Hydrolight, leading to inaccurate computations of the output radiances. The spectral shape of the differences between model simulations and measurements is described by Hydrolight assumptions about the fluorescence quantum yield and $a_{\mathrm{ph}} *(\lambda)$ (red wavelengths) and ac-9 scattering corrections (blue wavelengths).

VSF assumptions and ac-9 scattering correction errors likely explain the differences in percent errors between inshore and offshore stations (in relation to the turbidity front; Tables 1-4). Generally speaking, mismatches are greater in the more turbid inshore stations because of the presence of higher concentrations of particles and thus higher scattering and higher chlorophyll concentrations.
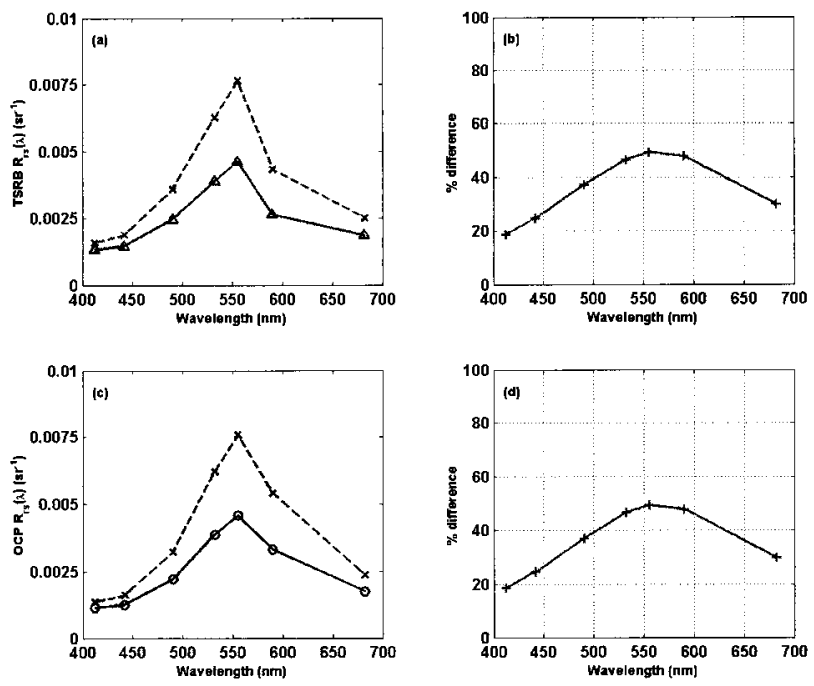

Fig. 5. $\quad R_{\mathrm{rs}}(\lambda)=L_{u}(\lambda, 0.66 \mathrm{~m}) / E_{d}\left(\lambda, 0^{+} \mathrm{m}\right)$ (dashed curve with crosses) compared with $R_{\mathrm{rs}}(\lambda)=L_{w}\left(\lambda, 0^{+} \mathrm{m}\right) / E_{d}\left(\lambda, 0^{+} \mathrm{m}\right.$ ) (solid curves with symbols) for measurements $\sim 5 \mathrm{~km}$ offshore of the turbidity front $\left(39.41^{\circ} \mathrm{N}, 74.20^{\circ} \mathrm{W}\right)$. HyperTSRB data are shown in (a) and (b) and OCP data are illustrated in (c) and (d). Differences were computed by Eq. (4) and are shown in the right-hand column.

\section{B. $R_{\mathrm{rs}}(\lambda)$ Measurements and Closure}

Direct measurements of $R_{\mathrm{rs}}(\lambda)$ cannot be made, and various methodologies have been utilized in its determination. ${ }^{11}$ Figure 5 shows that, when the simplistic approach TSRB- or HyperTSRB-measured $L_{u}(\lambda$, $0.66 \mathrm{~m}) / E_{d}\left(\lambda, 0^{+} \mathrm{m}\right)$ is used for estimates of $R_{\mathrm{rs}}(\lambda)$, it leads to errors of up to $50 \%$ in the green wavelengths as compared with $R_{\mathrm{rs}}(\lambda)=L_{w}(\lambda) / E_{d}\left(\lambda, 0^{+} \mathrm{m}\right)$ [see Eq. (3)]. Techniques to derive $L_{w}(\lambda)$ from in situ measurements of $L_{u}(\lambda, z)$ are briefly described in this paper. However, all these derivations require additional supporting measurements, e.g., IOPs for Hydrolight modeling (spectral absorption, attenuation or scattering coefficients, VSF measurements, chlorophyll concentration, chlorophyll-specific absorption) or profiled or multisensor $L_{u}(\lambda, z)$ measurements for empirical extractions together with above-water measurements of $E_{d}(\lambda)$.

The simplest technique for accurate, direct determinations of $R_{\mathrm{rs}}(\lambda)$ from in situ measurements (a TSRB or HyperTSRB) may be to include an additional upwelling radiance sensor at a depth different from $0.66 \mathrm{~m} .{ }^{13}$ The two radiance sensors would be used to calculate the diffuse attenuation coefficient for upwelling radiance by Eq. (2). $K_{L}(\lambda)$ would then be used to extrapolate $L_{u}(\lambda, z)$ to $L_{w}(\lambda)$ following Eq. (3). The HyperTSRB would also provide downwelling irradiance above the sea surface, $E_{d}\left(\lambda, 0^{+}\right)$.

\section{Summary}

In situ observations of upwelling radiance were made during the HyCODE project in coastal New Jersey $(<25$-m water depth) waters with two different methods: (1) surface-buoy HyperTSRB and (2) profiling OCPs. These measurements were compared with 
model estimates that used complementary measurements of IOPs for Hydrolight 4.1 model inputs. $K_{L}(\lambda)$ was computed with data from the OCPs to determine $L_{u}(\lambda, 0.66 \mathrm{~m}), L_{u}\left(\lambda, 0^{-}\right.$), and $L_{w}(\lambda)$ (also with the $n$-squared law for radiance). Average agreement between HyperTSRB and OCP determinations of $L_{w}(\lambda)$ was $26 \%, 13 \%$, and $17 \%$ at blue, green, and red wavelengths, respectively; average $r^{2}$ was 0.95. Comparisons of HyperTSRB (and OCP) $L_{w}(\lambda)$ with Hydrolight simulations yielded percent differences of $17 \%$ (18\%), 17\% (18\%), and 13\% (20\%) for blue, green, and red wavelengths, respectively. The average $r^{2}$ was 0.94 for HyperTSRB and 0.98 for OCP comparisons with Hydrolight. Differences are attributed to Hydrolight assumptions about the chlorophyll fluorescence quantum efficiency and the spectral chlorophyll-specific absorption coefficient, scattering corrections for ac-9 absorption data used in Hydrolight, and errors and assumptions associated with VSF measurements. Radiance measurement inaccuracies also contributed to discrepancies, with the largest source of error being the differences in the depth of the $L_{u}(\lambda, z)$ sensor on the HyperTSRB. Mismatches are, in general, greater in the more turbid inshore stations because of the presence of higher concentrations of particles and thus higher scattering and higher chlorophyll concentrations.

We suggest techniques for estimating $R_{\mathrm{rs}}(\lambda)$ using in situ measurements. This method involves the inclusion of an additional upwelling radiance sensor on a TSRB or HyperTSRB at a depth different from $0.66 \mathrm{~m}$. The two sensors would be used to compute $K_{L}(\lambda)$ and then be used to extrapolate $L_{u}(\lambda, z)$ to $L_{w}(\lambda)$.

Differences between measured and modeled upwelling and water-leaving radiances and remotesensing reflectances were within $20 \%$. This is an important step forward in the understanding of closure of IOPs and AOPs between models and data for coastal waters. Advancement of optical instrumentation technology now affords us the tools to improve our measurements and thus radiative transfer models. For example, newly developed scattering instruments ${ }^{23}$ now provide direct measurements of the VSF rather than one having to rely on coarsely resolved data sets collected more than 20 years ago. ${ }^{34}$

This research was supported by the U.S. Office of Naval Research Environmental Optics Program as part of the HyCODE program. We thank François Baratange for his help in data collection and processing.

\section{References}

1. S. A. Garver, D. A. Siegel, and B. G. Mitchell, "Variability in near-surface particulate absorption spectra: what can a satellite ocean color imager see?," Limnol. Oceanogr. 39, 13491367 (1994).

2. S. Tassan, "Local algorithms using SeaWiFS data for the retrieval of phytoplankton, pigments, suspended sediment, and yellow substance in coastal waters," Appl. Opt. 33, 2369-2378 (1994).

3. C. S. Roesler and M. J. Perry, "In situ phytoplankton absorp- tion, fluorescence emission, and particulate backscattering spectra determined from reflectance," J. Geophys. Res. 100, 13279-13294 (1995).

4. R. W. Gould and R. A. Arnone, "Three-dimensional modelling of inherent optical properties in a coastal environment: coupling ocean colour imagery and in situ measurements," Int. J. Remote Sens. 19, 2141-2159 (1998).

5. J. E. O'Reilly, S. Maritorena, B. G. Mitchell, D. A. Siegel, K. L. Carder, S. A. Garver, M. Kahru, and C. McClain, "Ocean color chlorophyll algorithms for SeaWiFS,” J. Geophys. Res. 103, 24937-24953 (1998).

6. M.-X. He, Z.-S. Liu, K.-P. Du, L.-P. Li, R. Chen, K. L. Carder, and Z.-P. Lee, "Retrieval of chlorophyll from remote-sensing reflectance in the China seas," Appl. Opt. 39, 2467-2474 (2000).

7. A. H. Barnard, A. D. Weidemann, W. S. Pegau, J. R. V. Zaneveld, J. W. Rhea, and C. O. Davis, "Hyperspectral remote sensing imagery and the detection of subsurface features," presented at Ocean Optics XV, Monte Carlo, Monaco, 16-20 October 2000.

8. O. Frette, S. R. Erga, J. J. Stamnes, and K. Stamnes, "Optical remote sensing of waters with vertical structure," Appl. Opt. 40, 1478-1487 (2001).

9. A. D. Weidemann, D. J. Johnson, R. J. Holyer, W. S. Pegau, L. A. Jugan, and J. C. Sandidge, "Remote imaging of internal solitons in the coastal ocean," Remote Sens. Environ. 76, 260267 (2001).

10. H. M. Dierssen, R. C. Zimmerman, R. A. Leathers, T. V. Downes, and C. O. Davis, "Remote sensing of bathymetry and seagrass in the Bahamas Banks using high resolution airborne imagery," Limnol. Oceanogr. 48, 444-455 (2003).

11. C. D. Mobley, "Estimation of the remote-sensing reflectance from above-surface measurements," Appl. Opt. 38, 7442-7455 (1999).

12. D. A. Toole, D. A. Siegel, D. W. Menzies, M. J. Neumann, and R. C. Smith, "Remote-sensing reflectance determinations in the coastal ocean environment: impact of instrumental characteristics and environmental variability," Appl. Opt. 39, 456469 (2000).

13. D. D. R. Kohler and W. D. Philpot, "Comparing in situ and remotely sensed measurements in optically shallow waters," presented at Ocean Optics XV, Monte Carlo, Monaco, 16-20 October 2000.

14. H. R. Gordon and M. Wang, "Surface-roughness considerations for atmospheric correction of ocean color sensors. II. Error in the retrieved water-leaving radiance," Appl. Opt. 31, 42614267 (1992).

15. X. Zhang, M. Lewis, and B. Johnson, "Influence of bubbles on scattering of light in the ocean," Appl. Opt. 37, 6525-6536 (1998).

16. J. R. V. Zaneveld, E. Boss, and A. Barnard, "Influence of surface waves on measured and modeled irradiance profiles," Appl. Opt. 40, 1442-1449 (2001).

17. H. R. Gordon and K. Ding, "Self-shading of in-water optical instruments," Limnol. Oceanogr. 37, 491-500 (1992).

18. R. A. Leathers, T. V. Downes, and C. D. Mobley, "Self-shading correction for upwelling sea-surface radiance measurements made with buoyed instruments," Opt. Exp. 8, 561-570 (2001); http://www.opticsexpress.org.

19. M. Lewis, Satlantic, http://www.satlantic.com/.

20. C. D. Mobley, Light and Water: Radiative Transfer in Natural Waters (Academic, San Diego, Calif., 1994).

21. H. Van Zee, "Underwater optical sensors-WET Labs," http:// www.wetlabs.com.

22. G. C. Chang, "Analyses of bio-optical variability related to physical processes on the southern New England continental shelf: July 1996-June 1997," Ph.D. dissertation (Ocean 
Physics Laboratory, University of California, Santa Barbara, 1999).

23. M. E. Lee and M. R. Lewis, "Measurement of the optical volume scattering function in the upper ocean," J. Atmos. Oceanic Technol., accepted for publication.

24. R. M. Pope and E. S. Fry, "Absorption spectrum (380-700 nm) of pure water. II. Integrating cavity measurements," Appl. Opt. 36, 8710-8723 (1997).

25. L. Prieur and S. Sathyendranath, "An optical classification of coastal and oceanic waters based on the specific spectral absorption curves of phytoplankton pigments, dissolved organic matter, and other particulate materials," Limnol. Oceanogr. 26, 671-689 (1981).

26. K. J. Waters, "Effects of Raman scattering on the waterleaving radiance," J. Geophys. Res. 100, 13151-13161 (1995).

27. H. R. Gordon, "Contribution of Raman scattering to waterleaving radiance: a reexamination,” Appl. Opt. 38, 31663174 (1999).

28. F. Barantage, College of Oceanic and Atmospheric Sciences, Oregon State University, Corvallis, Ore. 97331 (personal communication, 2002).

29. S. B. Hooker, S. McLean, J. Sherman, M. Small, G. Lazin, G. Zibordi, and J. Brown, The Seventh SeaWiFS Intercalibration
Round-Robin Experiment (SIRREX-7), March 1999, SeaWiFS Postlaunch Technical Series, Vol. 17, S. B. Hooker and E. R. Firestone, eds. (NASA Goddard Space Flight Center, Greenbelt, Md., 2002).

30. J. R. V. Zaneveld, J. C. Kitchen, and C. Moore, "The scattering error correction of reflecting-tube absorption meters," in Ocean Optics XII, S. G. Ackleson, ed., Proc. SPIE 2258, 44-55 (1994).

31. G. C. Chang, T. D. Dickey, O. M. Schofield, A. D. Weidemann, E. Boss, W. S. Pegau, M. A. Moline, and S. M. Glenn, "Nearshore physical processes and bio-optical properties in the New York Bight,” J. Geophys. Res. 107, 10.1029/2001JC001018 (2002).

32. T. K. Westberry, "Phytoplankton natural fluorescence variability and primary production in the Sargasso Sea," M.S. thesis (Institute for Computational Earth Systems, Science, University of California, Santa Barbara, Calif., 2001).

33. C. D. Mobley, L. K. Sundman, and E. Boss, "Phase function effects on oceanic light fields," Appl. Opt. 41, 1035-1050 (2002).

34. T. J. Petzold, "Volume scattering functions for selected ocean waters," Tech. Rep. SIO 72-78 (Scripps Institution of Oceanography, San Diego, Calif., 1972). 